\title{
Assessing market-based conservation governance approaches: a socio-economic profile of Indonesian markets for wild birds
}

\author{
PaUl JePSON, RichaRd J. La DLE and SuJATNiKa
}

\begin{abstract}
One of the most difficult situations for conservation is where state capacity to regulate is weak, major corporate organizations are absent, and the population does not have a strong culture of wildlife conservation. All these apply to the hugely popular urban Indonesian pastime of keeping wild songbirds, thought to be responsible for rolling local extinctions of several native species. In such situations the introduction of a voluntary, market-based approach could interact with regulation to create new and more effective approaches to reducing the negative conservation impacts of the associated trade. Here we assess the potential of such an approach through an in-depth analysis of the socio-economic and cultural aspects of bird keeping. We project that overall the pastime contributes USD 78.8 million to the economies of the six cities surveyed, supporting a range of associated small-scale rural and urban livelihoods relating to the production of cages and collection of live bird food. Finally, we describe five general birdbreeding models with the capacity to scale up the production of captive-bred birds that may substitute for wild-caught conspecifics. Based on this information we argue that a market-based policy instrument that is capable of shifting bird-keeping trends from wild-caught birds to captive-bred alternatives would align easily with macro-policy agendas in Indonesia relating to pro-poor growth and the creation of more and better jobs. Such a policy instrument could provide exciting opportunities for conservationists to engage the interest and support of non-conservation sectors in Indonesia in efforts to conserve diminishing populations of wild birds.
\end{abstract}

Keywords Bird keeping, CITES, conservation governance, conservation policy, Indonesia, market-led conservation, policy instrument, trade

PaUl JePson (Corresponding author) Biodiversity Research Group, Oxford University Centre for the Environment, University of Oxford, Dyson Perrins Building, South Parks Road, Oxford, OX1 3PS, UK. E-mail paul.jepson@ouce.ox.ac.uk

Richard J. LAdLE* Institute of Biological Sciences and Health, Federal University of Alagoas, Maceió, Alagoas, Brazil

Sujatnika Aksenta, Jl., Kebayoran Baru, Jakarta 12130, Indonesia

*Also at: Biodiversity Research Group, Oxford University Centre for the Environment, University of Oxford, Oxford, UK

Received 15 July 2010. Revision requested 7 October 2010.

Accepted 3 November 2010. First published online 17 October 2011.

\section{Introduction}

The international conservation movement is unified in 1 its aspiration that the trade and utilization of species should not endanger their wild populations. Over the past 4 decades the conservation movement has developed two contrasting approaches for dealing with the trade in wild species. The first is the creation of an international regulatory regime and supporting institutions, linked to domestic legislation, to control the harvest and international trade in specified species identified as being at risk of extinction. The 1973 Convention on International Trade in Endangered Species of Wild Fauna and Flora (CITES) is central to this approach and was developed when the state was the main body in conservation governance.

The second general approach involves the development of non-state, market-driven policy approaches that enrol market forces to embed environmental and social values within supply chains and the processes of production. These are now common in conservation, with schemes such as the Forest Stewardship Council and Marine Stewardship Council being among the most visible. Nonstate, market-driven approaches both respond to and are driving fundamental shifts in conservation governance. They represent new modes of governing conservation that involve multiple institutions and bodies and the deployment of techniques to strengthen support for conservation action and thereby mobilize change in individuals and organizations. Such governance approaches may operate independently of, or only loosely linked to, the state (Jordan et al., 2005; Lemos \& Agrawal, 2006).

Both regulatory and non-state, market-driven policy approaches have strengths and weaknesses and although each is increasingly inter-dependent they are often pursued by separate policy communities. The strengths of regulatory ('command and control') approaches to wildlife trade include their wide reach and their authority and influence with organizations and people committed to abiding by law. However, their effectiveness is dependent on: (1) the existence of sufficient political and bureaucratic will and resources to enforce policies on the ground, (2) accurate and up-to-date knowledge of population trends and responses to trade of target species, and (3) a public that is willing and able to abide by conservation regulations. In contrast, the value of market-based schemes lies in their ability to engage new bodies and people, create informal 
rule-making authority, extend conservation governance into areas where state regulation is weak, and promote public awareness of conservation issues. Moreover, they are more flexible than regulatory approaches. However, there are justifiable concerns that non-state, market-driven approaches lack regulatory strength, favour certain consumers and producers, lack a systematic focus or targeting and, at worst, are little more than marketing tools that support corporate 'greenwashing' (Gulbrandsen, 2004).

The keeping and trading of wild birds in Indonesia is an everyday practice: in Java and Bali a third of urban households in the six major cities are projected to keep a bird and this demand is causing rolling local extinctions of some wild bird populations and seriously depleting others (Jepson \& Ladle, 2006, 2009). The ubiquity of the bird-keeping hobby means it is impractical to govern using the current enforcement approach alone. In response, in 2005 we initiated a multi-agency project to develop and assess the feasibility of a complimentary non-state, marketdriven policy approach with four interlinking objectives: (1) to market captive-bred birds as more desirable than wild-caught birds on the basis of ethics and quality, (2) to increase the supply of captive-bred birds, (3) to set up a social marketing campaign to change attitudes and encourage ethical and sustainable bird purchasing choices, and (4) to establish a bird certification scheme (Jepson et al., 2008) to facilitate ethical consumption choices. Critically, this strategy was underpinned and is being informed by extensive quantitative and qualitative research on the demographic and geographical patterns of bird keeping (Jepson \& Ladle, 2009), attitudes towards birds and bird-keeping practices (Jepson, 2008, 2010), and the socioeconomic context of the bird trade.

In contrast to most other cases of successful marketdriven conservation, influential commercial bodies are absent in Indonesian bird-supply chains and therefore forms of governmental investment would probably be needed to finance a non-state, market-driven strategy. Successful implementation of such a strategy would therefore require a blended approach to wildlife governance involving state, commercial and citizen organizations. Crucially, this approach will need to include those whose conduct the policy mechanism seeks to alter. This will entail the identification and/or development of rationales that can transcend and unify diverse groups such that they believe in a policy's objectives, have political and/or material interests in it succeeding, and/or have co-produced it (Cashore et al., 2003; Bernstein \& Cashore, 2004).

Building on previous baseline studies (Jepson \& Ladle, 2005, 2009) our objective here is to assess the feasibility and effectiveness of the proposed non-state, market-driven approach, and how this could blend with the existing regulatory approach. We do this through a related set of socio-economic analyses that include: (1) the contribution of songbird keeping to urban economies and the forms of employment it supports and creates, (2) songbird supply chains, and (3) bird-breeding business models. Furthermore, we assess the degree to which our proposed approach could be aligned with current macro-policy themes in Indonesia, thereby attracting the attention of influential government policy bodies. Relevant themes include pro-poor growth and increasing the supply of better jobs (Manning, 2003; World Bank, 2006).

\section{The policy context}

Indonesia has a human population of 225.6 million of which 131.7 million reside on the islands of Java and Bali. The national work force is 144 million of which $20 \%$ are $15-24$ years of age and $16.2 \%$ work $<25$ hours per week. In urban areas $24 \%$ of the workforce earns an average of IDR 300,000 (USD 33.00) month $^{-1}$. The provinces of Central and East Java have some of the highest levels of poverty in Indonesia $(>20 \%)$.

Indonesia is a priority country for international bird conservation investments because of its high number of bird species (1,539 species) and exceptional numbers of endemic (376) and threatened species (111; BirdLife International, 2011; Burung Nusantara, 2011). To date, bird conservation policy approaches have mostly been developed by international agencies working in partnership with the government Department of Forest Protection and Conservation, which is characterized by a top-down coercive governance model. The regulatory framework governing the keeping, trade and acquisition of wild birds has been developed through 3 decades of policy engagement between national government authorities and international conservation groups, notably TRAFFIC, BirdLife International and Wetlands International. It deploys the tools of fines, confiscation and imprisonment but does include limited education and awareness programmes. During the 1990 s concerns were raised about the scale of internal markets for wild-caught songbirds and the impacts of the popular bird-keeping pastime on wild bird populations both inside and outside reserves (Nash, 1993; Holmes, 1995).

Birds were the most popular household pet in six cities surveyed on Java and Bali in 2006. Of households surveyed $14.7 \%(262 / 1,781)$ kept a songbird and $27.7 \%(494 / 1,781)$ had kept a bird within the last 10 years (Jepson \& Ladle, 2009). Bird keeping has deep cultural roots in Indonesia. A birdin-a-cage is one of five symbols of a traditional Javanese knight, representing the importance of a hobby in a balanced life (Toer, 1984). Until recently the zebra dove Geopelia striata was the most popular cage bird but surveys in 1999 and 2006 (Jepson \& Ladle, 2006, 2009) revealed the rising popularity of songbirds. Trends in wider bird keeping are linked to fashions in the pastime of birdsong competitions. During the autocratic rule of President Suharto 
(1963-1997) competitions involving the zebra dove were the most prestigious because of presidential patronage. Since the mid 1990s a new form of songbird competition has emerged involving native species as well as locally bred canaries Serinus canaria and lovebirds Agapornis spp.. The appeal of these competitions lies in the high prize money, the engagement of urban-based entrepreneurial networks, and the fact that song quality is environmentally determined, creating opportunities for anyone to train and compete a bird acquired from the wild (Jepson, 2010). Competion songbirds are termed kicauan, and kicau-mania is a vibrant new cultural phenomenon in Indonesian cities. The bird-keeping hobby has its own weekly tabloid newspaper (Agrobis Burung, circulation 22,000) whose reporting is dominated by songbird contest and bird-breeding news, and that sets fashions and aspirations for the wider bird-keeping community.

The market for native zebra doves has long been supplied from local captive-breeding enterprises. In contrast seven of the nine commonest kicauan species are territorial forest species with low population densities: orange- and chestnut-capped thrushes (Zoothera citrina, Zoothera interpres), white-rumped shama Copsychus malabaricus, straw-headed bulbul Pycnonotus zeylanicus, greater green and blue-winged leafbird (Chloropsis sonnerati, Chloropsis cochinchinensis) and hill blue flycatcher Cyornis banyumas. The bird-keeping hobby is thought to have already caused the virtual extinction of straw-headed bulbul in the wild in Indonesia and decimated shama and thrush populations across Java, Sumatra and Borneo (Jepson \& Ladle, 2009). Moreover, several other forest species are used as so-called master birds: birds whose song phrase the competition species incorporate in their songs. Demand for master birds is dynamic and unpredictable, reflecting bird competition fashions (Jepson, 2008). Bird breeding is also a common pastime, although currently less organized than song competitions. Songbird breeding is both an income generating hobby and a business enterprise.

Competing and breeding birds form two distinct communities of practice (bird clubs, breeder associations) that could co-produce and be early adopters of a non-state, market-driven approach. A national organization, Pelestari Burung Indonesia (PBI), is a respected authority on issues relating to songbird competitions, bird breeding and conservation. It trains and accredits independent competition judges thereby helping assure the integrity of song competitions and provides technical support to breeders. In 2006 it adopted a policy that the songbird competitions it accredits (i.e. those using PBI judges) should convert to captive-bred birds by 2012. At the time of this study this policy (called 'ring' classes) had been introduced for one species, Z. interpres.

\section{Methods}

We adopted a two phase mixed methods approach (Greene et al., 1989). Phase one involved exploratory interviews and a large scale questionnaire survey to generate overview data on the scale and attributes of bird keeping, including its overall economic contribution, and to identify the key bodies and networks. The second qualitative phase consisted of in-depth interviews and workshops. There were three main objectives of this phase: firstly, to uncover insights on the contemporary culture of bird keeping in Indonesia (reported in Jepson, 2008, 2010); secondly, to map the networks of exchange and the different actors involved in bird-keeping practices; and thirdly, to identify prominent people and/or groups within the bird keeper fraternity and to engage them in efforts to co-produce voluntary approaches to reduce the impacts of bird keeping on wild bird populations. This second phase of research culminated in three workshops and three working groups that brought together prominent figures in the Indonesian bird-keeping and bird conservation communities to develop a certification scheme for birds as part of the broader policy approach (Jepson et al., 2008).

Jepson \& Ladle (2009) provide a comprehensive description of the questionnaire approach and methodology. The key features are: (1) We conducted face-to-face questionnaire interviews with 1,781 households in six cities (Jakarta, Bandung, Yogyakarta, Semarang, Surabaya on the island of Java and Denpassar on the island of Bali) using a stratified random sampling protocol; this was based on an established sampling frame used by the consumer survey company Nielsen-Indonesia for its regular household Omnibus surveys. (2) Because the incidence of birdkeeping households $(n=262)$ fell below that needed for robust analysis of keeping-related variables we added a booster sample of 192 bird-keeping households, also selected using the same stratified random sampling protocol. (3) The questionnaire comprised two parts, the first given to all respondents and the second only to birdkeeping households; the bird-keeping specific part included 18 questions on bird-related expenditure, sourcing birds, participation in songbird contests and attitudes to certification. (4) The questionnaire was administered by Burung (formerly BirdLife) Indonesia using teams trained by Nielsen-Indonesia. A 30\% recall protocol practice was adopted, whereby households were re-contacted by telephone the same day as the survey and randomly asked survey questions to assure sampling rigour and data quality. The data were analysed using SPSS $v .14$ (SPSS, Chicago, USA).

The structured qualitative research involved 85 interviews conducted between September 2006 and March 2008. Respondents were identified using a snowballing approach through PBI networks and by following supply chains of 
birds, bird food and products. In addition we conducted two additional structured interview surveys. The first, conducted between September 2006 and February 2007, involved visits to seven bird-breeding facilities representing five distinct bird-breeding facilities identified from exploratory interviews. The second, conducted in January and February 2007, was a telephone survey of 14 hobbyists and four trainers identified from the hobbyist publication Agrobis Burung and representing the four provinces of Java and Bali. Supply chains of birds were mapped in an iterative manner. A provisional network map was produced after each survey period and modified during subsequent interviews.

We projected the monetary contribution of songbird keeping to the economies of the six cities surveyed by multiplying the mean annual amount spent by songbird keepers in the previous year (on new birds, cages, bird food, medicines and supplements, bird keeping magazines and travel to and from song contests) by the projected number of households in the six cities surveyed that keep songbirds. We also investigated the relative economic contributions of songbird competitors, breeders, and casual/non-active keepers. We also compared the economic profiles of songbird keepers who indicated they enter birds in song contests (termed contestants) against all other songbird keepers (termed hobbyists). Data were analysed in two ways. Firstly, because there were many respondents who claimed not to regularly spend anything for particular expenditure categories, the relative frequency of hobbyists and contestants claiming to spend money were analysed for each category. Secondly, for those claiming to have made purchases, parametric tests were performed to compare the mean amount of money reported to be spent by hobbyists and contestants in each expense category.

\section{Results}

\section{Economic contribution of bird keepers to urban economies}

We project that bird keepers in the six cities surveyed spend USD 78.8 million per annum on their hobby (Table 1). If bird-related expenditure in these cities is representative of the urban population residing in smaller cities and towns then the projected spend for Java and Bali is c. USD 366.8 million. These figures omit the contribution of bird markets to city economies in terms of the rents and taxes they generate to local authorities (e.g. from kiosks, parking) and the direct and indirect employment generated by associated services (e.g. cafés, transport). Costs associated with keeping birds (cages and food) account for $58 \%$ of the total expenditure (Table 1). With the exception of the market for packaged bird food this economy is dominated by individual producers/collectors and small enterprises.

A total of $60 / 454$ songbird keepers indicated they competed birds in songbird contests. Significantly more songbird contestants than hobbyists claimed to spend money on new birds, live food, seed and grain, vitamins and minerals, medicine, veterinary expenses, bird-keeping magazines, and travelling to songbird club meetings and song contests (Table 2). Comparing respondents who claimed to have regular expenditure, contestants spent on average three times more than hobbyists on new birds and cages and more than four times as much on bird keeping equipment, and also spent significantly more on bird meal, live food, seed and grain, bird-keeping magazines, and travel to bird meetings and song contests (Table 3).

TABLE 1 Mean annual value of categories of expenditure on bird keeping in six cities of Java and Bali (in USD, with 95\% confidence interval) calculated from mean monthly expenditure reported in 2006, and projected spend for urban Java and Bali (in USD; see text for details), based on the following estimates for number of households from Nielson-Indonesia: Denpasar, 189,189 (forecasted data); West Java + Jakarta Urban, 9,294,000; Central Java + Yogya Urban, 5,083,000; East Java Region, 5,235,000. Exchange rate IDR $1=$ USD 0.0011 .

\begin{tabular}{lrr}
\hline & & \\
Expenditure category & \multicolumn{1}{c}{ Six cities of Java \& Bali } & Urban \\
Birds & $31,647,974(23,117,604-42,857,471)$ & $147,288,130$ \\
Bird cages & $8,843,453(6,459,795-11,975,743)$ & $41,156,997$ \\
Equipment & $3,662,041(2,674,977-4,959,111)$ & $17,042,961$ \\
Natural (live) food & $11,883,098(8,680,137-16,092,011)$ & $55,303,361$ \\
Fruit & $6,242,485(4,559,890-8,453,530)$ & $29,052,220$ \\
Seed \& grain & $2,762,435(2,017,850-3,740,870)$ & $12,856,236$ \\
Vitamins & $1,959,940(1,431,659-2,654,137)$ & $9,121,463$ \\
Medicines & $779,346(569,282-1,055,385)$ & $3,627,039$ \\
Vet fees & $277,787(202,912-376,177)$ & $1,292,806$ \\
Bird magazines & $887,374(648,192-1,201,676)$ & $4,129,796$ \\
Travel to meetings \& song contests & $9,884,577(7,220,296-13,385,627)$ & $46,002,341$ \\
Total & $78,830,509(57,582,596-106,751,738)$ & $366,873,350$ \\
\hline
\end{tabular}


TABle 2 Comparison of the percentage of hobbyists and song contest competitors who claimed to have regular expenditure in $2006\left(\mathrm{n}=454 ; \mathrm{df}=1\right.$ for all $\chi^{2}$ tests $)$.

\begin{tabular}{|c|c|c|c|c|}
\hline Expenditure category & Hobbyist & Contestant & $\chi^{2}$ & $\mathrm{P}$ \\
\hline New birds & 60.7 & 76.7 & 5.709 & 0.017 \\
\hline Cages & 54.3 & 68.3 & 4.156 & 0.041 \\
\hline $\begin{array}{r}\text { Bird-keeping } \\
\text { equipment }\end{array}$ & 56.3 & 70.0 & 3.989 & 0.046 \\
\hline Bird meal & 81.2 & 80.0 & 0.05 & 0.822 \\
\hline Live food & 58.9 & 73.3 & 4.562 & 0.033 \\
\hline Fruit & 47.0 & 58.3 & 2.699 & 0.100 \\
\hline Seed \& grain & 24.6 & 53.3 & 21.107 & $<0.001$ \\
\hline Vitamins \& minerals & 19.8 & 50.0 & 26.200 & $<0.001$ \\
\hline Medicine & 6.1 & 21.7 & 16.875 & $<0.001$ \\
\hline Veterinary expenses & 1.0 & 8.3 & 14.352 & $<0.001$ \\
\hline $\begin{array}{l}\text { Bird-keeping } \\
\text { magazines }\end{array}$ & 6.3 & 16.7 & 7.797 & 0.005 \\
\hline $\begin{array}{l}\text { Travel to meetings \& } \\
\text { song contests }\end{array}$ & 2.5 & 66.7 & 218.502 & $<0.001$ \\
\hline
\end{tabular}

\section{Associated economic activities}

Two of the economic activities, both with a large market value, provide sustainable business opportunities and livelihoods for individuals and families in lower socioeconomic groups. These are the collection, production and supply of wild food and the production of bird cages. Three examples are illustrative of the general situation. Firstly, the production of crickets and grasshoppers (an important dietary component for shrikes and shamas) is mostly a home side-business. A typical household produces $2 \mathrm{~kg}$ of crickets per week and sells to an agent or local market for IDR 40,000 (USD 4.40) $\mathrm{kg}^{-1}$. The agent sells crickets to shops for IDR 60,000 (USD 6.60 ) $\mathrm{kg}^{-1}$ and they retail at IDR 50 (USD 0.005) cricket $^{-1}\left(=\right.$ USD 9-11 $\left.\mathrm{kg}^{-1}\right)$. A second essential live food is eggs of the Asian weaver ant Oecophylla smaragdina. One Jakarta-based distributor supplies c. $100 \mathrm{~kg}$ of ants' eggs daily to outlets for IDR
55,000 (USD 6.10) $\mathrm{kg}^{-1}$ (one-fifth of the estimated total supply). He sources eggs from an agent in Lampung (South Sumatra) for IDR 35,000 (USD 3.8) $\mathrm{kg}^{-1}$ (plus transport costs) who buys from agricultural workers who typically collect $0.8 \mathrm{~kg}$ of eggs daily from fruit-tree plantations. Finally, a business surveyed in Bandung assembles and decorates cages to produce c. 5,000 branded products per year. Based on data from our interviews we tentatively estimate the annual turnover is IDR 1.4 billion (USD $156,000)$ year $^{-1}$. The business directly employs 25 workers and indirectly generates employment in a local metal workshop (10 workers), a fibreglass workshop (three workers), a wood ball manufacturer (seven workers), in addition to the estimated 80-100 village-based cage makers who receive employment.

In contrast to live food the market for packaged bird food (grains and meal) is dominated by three large companies who import the grains that they either blend or manufacture into pellets and package in Indonesia. These companies are actively seeking to expand and secure their market share through improving and differentiating their products. The current focus of innovations is on nutritional supplements to promote better song capabilities and protect birds against avian influenza. Owners of two of the companies see new markets in the expansion of bird breeding and one offered to sponsor initiatives to promote the prestige of ring classes (captive-bred birds) at song contests.

The songbird contest itself generates a range of business and livelihood opportunities because it creates high value supply chains and stimulates entrepreneurship among breeders and trainers. No betting takes place at song contests but prize money is significant and, crucially, the value of a bird increases markedly when it wins or does well. Many hobbyists speculate on such increases by buying promising young birds and then training and reselling them. For example, in the case of orange-headed thrush this

TABLE 3 Comparison of reported mean monthly expenditure \pm SE (USD; untransformed data) by hobbyists and song contest competitors in 2006. All $t$-tests were on log transformed data.

\begin{tabular}{|c|c|c|c|c|c|}
\hline Expenditure category & Hobbyist & Contestant & $t$ & $\mathrm{df}$ & $\mathrm{P}$ \\
\hline New birds & $31.49 \pm 4.43$ & $133.89 \pm 24.31$ & 4.144 & 449 & $<0.001$ \\
\hline Cages & $8.62 \pm 1.33$ & $38.45 \pm 8.04$ & 3.660 & 447 & $<0.001$ \\
\hline Bird-keeping equipment & $3.25 \pm 0.67$ & $18.06 \pm 8.74$ & 1.690 & 448 & 0.096 \\
\hline Bird meal & $22.02 \pm 3.14$ & $16.22 \pm 1.84$ & 1.59 & 441 & 0.115 \\
\hline Live food & $17.57 \pm 1.76$ & $52.97 \pm 9.40$ & 3.701 & 449 & $<0.001$ \\
\hline Fruit & $8.46 \pm 1.61$ & $12.12 \pm 2.86$ & 0.861 & 444 & 0.390 \\
\hline Seed \& grain & $3.10 \pm 0.49$ & $9.42 \pm 2.34$ & 2.065 & 440 & 0.010 \\
\hline Vitamins \& minerals & $2.35 \pm 0.39$ & $5.76 \pm 1.34$ & 2.626 & 443 & 0.011 \\
\hline Medicine & $0.71 \pm 0.19$ & $3.64 \pm 1.39$ & 2.081 & 440 & 0.042 \\
\hline Veterinary expenses & $0.18 \pm 0.11$ & $1.87 \pm 0.83$ & 2.007 & 434 & 0.049 \\
\hline Bird-keeping magazines & $0.78 \pm 0.21$ & $3.36 \pm 1.15$ & 2.194 & 434 & 0.032 \\
\hline Travel to meetings \& song contests & $1.89 \pm 0.93$ & $91.78 \pm 17.66$ & 5.082 & 440 & $<0.001$ \\
\hline
\end{tabular}


practice is common for birds valued below IDR 50 million (USD 5,550). When champion birds are sold (a rare occurrence) they can cost as much as IDR 300 million (USD 33,300). At the top end of the value chain there are people who scout up-and-coming birds and assess the value of birds on behalf of wealthy hobbyists.

\section{The songbird supply chain}

We identified 13 actors engaged in the creation of supply chains in songbirds (Table 4). These actors structure supply chains into lower value, high volume supply chains supplying the general bird keeper and high value, lower volume supply chains supplying the hobbyist (Fig. 1). On Java and Bali birds are caught from the wild by either rural residents or groups of friends who go bird trapping. The latter typically trap higher value songbirds (e.g. leafbird species and magpie robin Copsychus saularis) and sell to shop owners in rural villages (IDR 150,000 (USD 17) for orangeheaded thrush) who condition the birds before selling them on to bird shops (IDR 275,000 (USD 31)) in a nearby town. Non-recreational bird catchers may also sell to this supply chain but more often sell low value species (e.g. bulbuls Pycnotus spp., white-eyes Zosterops spp. and munias Loncura spp.) directly to bird shops in a nearby town.

Quality birds may circulate in urban supply networks whilst poorly performing birds are sold to bird markets and re-enter the lower value supply chains. Bird breeders sell lower quality birds to bird markets and kiosks. Better quality birds and species in short supply (such as the competition species) are sold or exchanged with other breeders and increasingly to competition hobbyists. The orange-headed thrush supply chain is unusual because it now involves the harvesting of chicks from agro-forests in Bali (Kristianto \& Jepson, 2011).

\section{Bird-breeding business models}

In 2008 the PBI had a registry of over 400 bird breeders (Endang Sri Utami, pers. comm.) and there may be many more. The number of people breeding the song-competition species is increasing. Two reasons were offered: successfully breeding these popular and difficult to breed forest species brings prestige, and as wild sources diminish breeding

TABLE 4 A summary of livelihood activities associated with supply chains of songbirds in Java and Bali, Indonesia. Words in italics are mostly close derivations from the English, used by hobbyists (Indonesian spelling is used).

\begin{tabular}{|c|c|}
\hline Type & Activities \\
\hline Catcher/harvester & Traps \&/or harvests wild birds \\
\hline Village trader/agent & $\begin{array}{l}\text { Conditions wild birds to live in cages \& eat prepared food. Sells birds to local bird shops \& } \\
\text { bird markets. }\end{array}$ \\
\hline Agent/supplier (agen) & $\begin{array}{l}\text { Either collects birds from a region \& sells to bird wholesaler or trainer/speculator, or } \\
\text { collects live food \& sells to city bird shops }\end{array}$ \\
\hline Breeder & $\begin{array}{l}\text { Breeds birds for sale or exchange. May provide consulting services to other breeders } \\
\text { (e.g. bird farms). }\end{array}$ \\
\hline Wholesaler & $\begin{array}{l}\text { Typically owns a shop in a bird market. Buys from agents \& sells to other wholesalers, the } \\
\text { public \& hobbyists. May send own agents to work with local agents to secure supplies. } \\
\text { May have teams of door-to-door sellers (pikul burung) who sell to local bird shops \& } \\
\text { direct to households. }\end{array}$ \\
\hline Bird shop (kiosk) owner & $\begin{array}{l}\text { Located in neighbourhood shopping areas (may cluster). Sells birds, cages \& food. } \\
\text { Supplied by agents (birds, food \& cages) \& sometimes local farmers (birds \& food). }\end{array}$ \\
\hline Bird keeper & Buys birds for enjoyment \& general interest. Some try breeding. \\
\hline Hobbyist (song contests) & $\begin{array}{l}\text { Buys, exchanges \& trains birds to compete at song contests held across Java, \& in Bali \& } \\
\text { East Kalimantan. Many hobbyists join informal bird clubs, others are single fighters. }\end{array}$ \\
\hline Bird dealer/speculator & $\begin{array}{l}\text { Selects best chicks \& young birds from agents \& local song contests. Trains birds to enter } \\
\text { song contests \& sells as prospects. Assesses competition level that a bird can reach \& sets } \\
\text { the entry-point value of song-contest species. }\end{array}$ \\
\hline Broker/scout (tester) & $\begin{array}{l}\text { Identifies exciting prospects. Advises leading hobbyists on their bird purchases \& broker } \\
\text { deals. Buys \& sells if has own funds. }\end{array}$ \\
\hline Trainer $(j o k i)$ & $\begin{array}{l}\text { Trains song-contest birds on behalf of owner. Manages junior bird keepers, entering \& } \\
\text { transporting birds to song contests. }\end{array}$ \\
\hline Song contest organizer (organisier) & $\begin{array}{l}\text { Organizes \& manages event, including permits, rent of a site, equipment, hiring, security, } \\
\text { marketing, securing sponsorship, collecting entrance fees \& paying prize monies. Self } \\
\text { finances smaller events but usually organizes larger events on behalf of a patron. }\end{array}$ \\
\hline Bird-keeping media & $\begin{array}{l}\text { Report ( \& construct) trends in bird keeping, tips on keeping, training \& breeding birds, } \\
\text { innovations in breeding, results of song contests \& news of winning owners \& clubs. } \\
\text { Editors \& journalists connect different bodies \& people. }\end{array}$ \\
\hline
\end{tabular}




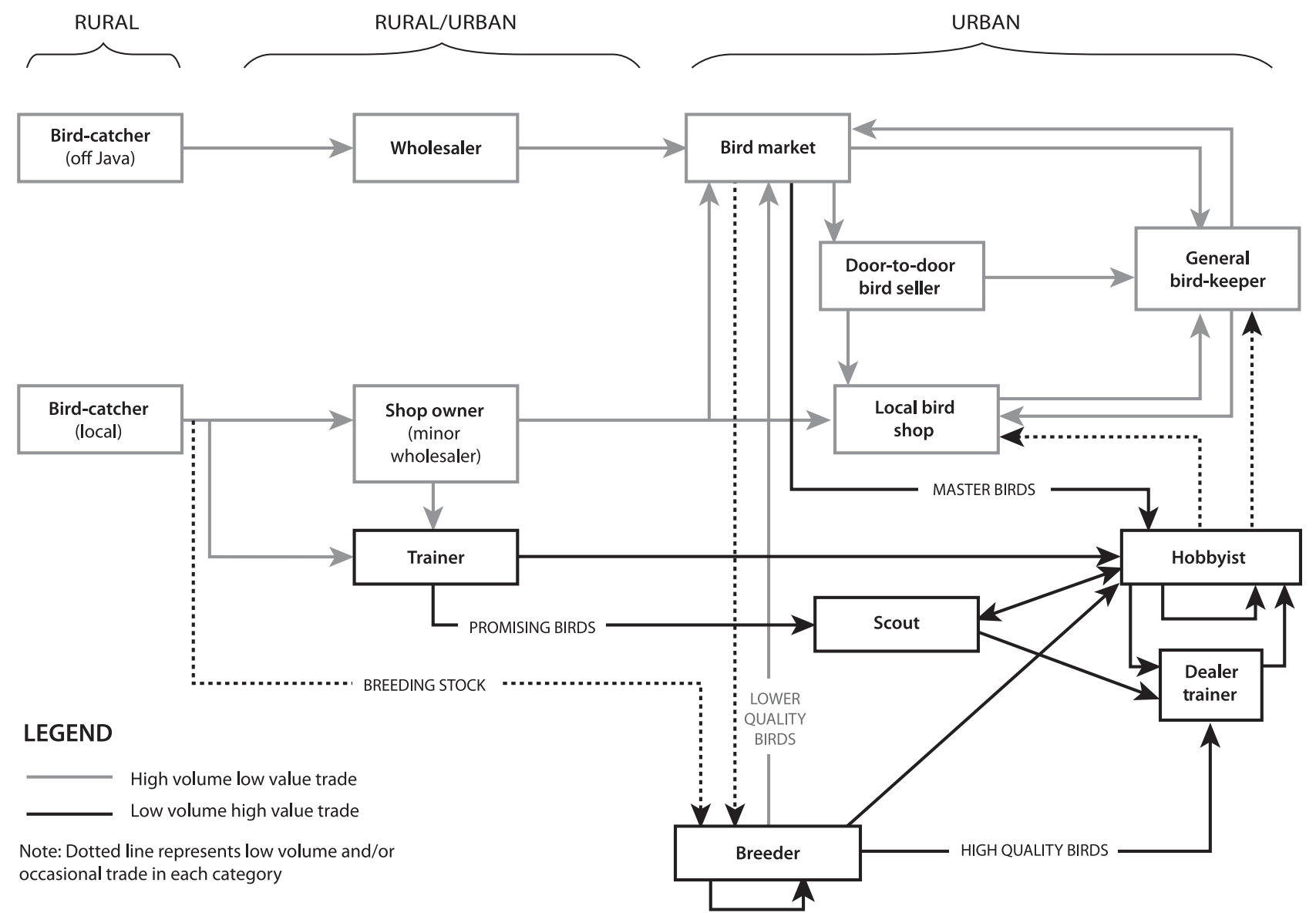

FIG. 1 Schematic of songbird supply chains operating in Java, Indonesia.

becomes more profitable. We identified five general business models for bird breeding: (1) independent breeder, (2) breeder with outsourcing, (3) breeder association, (4) village cooperative, and (5) commercial-scale bird farm. In addition many amateur bird keepers breed and sell popular domestic species such as canaries, lovebirds and budgerigars Melopsittacus undulatus. The first three models are the locus of innovation for techniques to breed and rear songbirds. Central to each is a technically adept individual with a passion for developing new breeding and husbandry techniques.

An example of an independent breeder is a Jakarta-based businessman and owner of a famous champion whiterumped shama. He developed a technique that prompted these aggressive and highly territorial forest species to mate within 20 minutes and, at the time of the interview, had a breeding stock of $25-30$ pairs. He sold young birds to a people on a waiting list at IDR 2.5 million (USD 285) per pair. His reputation as a breeder of champion birds generated a premium of USD 115 above the normal market price of USD 170 for a pair of captive-bred shamas. He sold birds at a lower price to genuine enthusiasts who wanted to breed shamas and sold surplus birds to brokers from the Pramuka bird market in Jakarta.
The breeder with outsourcing model, known as intiplasma, is exemplified by a breeder in the city of Solo specializing in straw-headed bulbuls and selling to wealthy clients. As the inti (nucleus) he has a sizeable breeding facility of 20 breeding pairs but enters into contracts with independent bird breeders (plasma) where he retains a stake in the breeding stock and production. Under this arrangement he provides a breeding pair worth IDR 10 million (USD 1,140; the species is difficult to pair) to an individual breeder who is obliged to give back two pairs and sell back two pairs (at IDR 5 million per pair) to repay the loan. The plasma is free to build up his own breeding stock but is expected to sell his future production back to the inti. Both parties benefit: the plasma gains a loan of breeding stock, access to expert breeder knowledge and to markets, the inti gains from financial risk spreading, lower direct costs, more birds to sell, and the ability to call in birds if his breeding stock is low or at risk of in-breeding. This particular breeder employs boys from a local orphanage who he trains to work as bird keepers for his wealthy clients.

A leading example of a breeder association is the Association of Straw-headed Bulbul Breeders who have actively been increasing their membership through promotions at 
song contests and agricultural shows. They now have 63 members in Sumatra, Kalimantan and Java each owning an average of 15 breeding cages. The Association has produced a comprehensive business analysis for different startup models and provides a range of additional technical advice for would-be breeders.

The village of Klaten in Central Java is an example of a village cooperative breeding business model. The business was initiated during the economic crisis of 1997 by two residents who started breeding canaries but quickly changed to Asian pied starling Sturnus contra, which was in demand as a 'master bird'. Neighbours took up their idea and some invested their redundancy money. In addition, the village secured a IDR 6 million development grant from the district council to buy additional breeding stock. The cooperative now has 60 members (families). Each family is responsible for their own business and different families adopt different roles. Some manage the full cycle of mating, incubation, and rearing to adults. Other families only rear chicks (either young 318 days or $18-50$ days). They either buy the chicks from a breeder or are paid by the breeders to raise chicks on their behalf. The cooperative sets the minimum price for birds from the village and collectively organizes and pays for advertising.

The final category of breeding business model is the commercial-scale bird farm. One surveyed in Jakarta previously specialized in breeding champion (pedigree) zebra doves but in 2003 constructed facilities to breed strawheaded bulbul (8o cages), white-rumped shama (36 cages), Asian pied starling (12 cages), chestnut-capped thrush (five cages) and canary (five cages). The investment was IDR 1 billion (USD 114,485) for cages and breeding stock. Monthly operating costs are IDR 20 million (USD 2,222) including wages for nine staff. The enterprise started selling birds in 2006 and is currently selling birds to a value of IDR 2030 million (USD 2,222-3,333) per month. However, they estimate that the 50 straw-headed bulbul cages could generate IDR 120 million (USD 13,333) month ${ }^{-1}$ once they have perfected their breeding techniques.

\section{Discussion}

We have previously quantified the huge numbers of bird keepers on Java and Bali and the large volume of native wild birds caught to support their pastimes (Jepson \& Ladle, 2006, 2009). The data presented here quantify the important contribution of bird keeping to urban economies and provide insights into the rich social and entrepreneurial networks associated with bird-related transactions. This, in combination with the mapping of supply chains, supports new thinking on how to design, blend and target regulatory and market-based approaches in a manner that will achieve conservation outcomes whilst promoting livelihood opportunities.

The data presented on economic and employment contributions reinforce our earlier conclusion (Jepson \&
Ladle, 2009) that it would be impractical and undesirable to govern this practice using regulatory approaches alone, and that a mixed approach is required that combines government regulations and efforts to bring about changes in people's views with targeted market interventions. A key finding of our study is that practices associated with the growing popularity of keeping, breeding, training and competing songbirds, which represents a major threat to wild bird populations, are contributing to the realization of macro-policy themes of pro-poor growth and more, better jobs.

A broad-based non-state, market-driven approach that mobilizes a switch from wild-caught to captive-bred birds has great potential for aligning with these macro-policy themes and attracting the engagement of influential policy bodies and organizations from the economic and employment arenas. Increasing the proportion of captive-bred birds in the market will create jobs because people will need to replicate the collection of food and feeding of chicks provided by nature. Moreover, a system of captive breeding better serves poor people and those aspiring to better jobs than the current system of wild-caught supply by replacing a simple cash transaction at each point in the supply chain with a more complex, stable and predictable structure involving networks of personal relationships. The production and supply of bird food also generates opportunities for people who are housebound, uneducated and/or with limited resources. Césard (2004) reports that many rural families in west Java gain a significant proportion of their subsistence income from such activities. Such enterprises require minimal financial investment and can be developed into profitable side businesses or thriving small businesses.

A number of factors suggest that with appropriate investment and support bird breeding could be expanded significantly. In particular three business models (intiplasma, breeder associations and village cooperatives) lend themselves to rapid scaling up because start-up costs are relatively modest, emerging associations and networks of knowledge exchange provide low cost access to techniques, expertise and breeding stock, and there is an abundance of low cost casual labour to undertake time-consuming tasks. Furthermore, the deep cultural roots of bird keeping in Indonesia make it an attractive business proposition.

We also identified a number of challenges and issues to expanding captive breeding beyond the technical challenges of procuring stock and developing robust and effective husbandry techniques. For example, this strategy might exacerbate rural-urban inequalities. This is because breeding songbirds in urban areas appears to be more successful and cost effective than in rural areas on account of there being fewer rats, snakes and civet cats that disturb or eat the birds. In addition, it is unclear whether bird breeding falls under the licensing authority of the Ministry of Forestry, of 
Agriculture or of Industry and Trade. This makes breeding enterprises vulnerable to the rent-seeking behaviours of multiple local departments. In cities it is easier to reduce the visibility of an enterprise and enlist the support of influential networks than is the case in villages. A second challenge to successful expansion of captive breeding is that in Indonesia the formal policy partners of conservation groups are the Ministry of Forestry and the resource management departments of various inter-governmental agencies. Their remits focus on, and in some cases are restricted to, livelihood development in rural areas, such as around protected areas. The urban focus of our proposed approach does not align with this focus.

Additionally, it was impossible to ascertain whether captive-bred birds could be produced at prices comparable to their wild-caught counterparts. This is because price differentials involve a complex interplay of prestige, supply, developments in breeding techniques and consumer preference. The general view of hobbyists and breeders is that until a species is extremely rare wild-caught birds will be cheaper than a captive-bred alternative. However, some thought that many consumers would be willing to pay a premium for captive-bred birds. Clearly, the potential for significant shifts in the attitudes of urban bird keepers is also an important prerequisite for the successful implementation of any conservation intervention strategy based on substitution of wild-caught songbirds.

Our study did not specifically consider the refinement of regulatory instruments. Our supply chain mapping, however, shows that the wholesale shipment of birds to Java from the outer island represents a pressing conservation problem and that new sources of birds created by expanding road infrastructure undermines market incentives to develop breeding of songbirds. Currently only the trade of protected species is regulated but the difficulty of distinguishing protected from non-protected species contributes to the weak regulation of these high volume, low value supply chains. We therefore propose a blended governance approach that combines incentives to expand self regulation and the breeding and marketing of certified birds in the cities with stricter regulation of wholesale supply chains from Sumatra, Kalimantan and Nusa Tengarra. One means of strengthening regulation could be to engage Indonesia's active animal welfare movement. Among bird breeders and hobbyists entering birds in song contests welfare standards are high and responses to welfare-related questions in our questionnaire survey (not reported here) suggests there could be considerable popular support for regulating bird transport.

Policy in any area must proceed with incomplete scientific evidence and reflect dominant ideologies, political agendas, public opinion and financial realities. This new body of evidence on the scale of domestic markets for wild birds in Indonesia calls for renewed and concerted efforts to mitigate the impacts of bird keeping on wild bird popula- tions. We argue that, in Indonesia at least, conservationists need to move beyond the moralistic, animal rights and protectionist logic that dominate much wildlife trade discourse and embrace the development logic of pro-poor growth and more, better jobs.

There are grounds to believe that a strategy of developing captive-bred supply and regulation targeting wholesale supply chains would help establish a stronger cultural basis for conservation in Indonesia. This is because there are several conservation-minded individuals and groups within the bird-keeping fraternity and the approach outlined would support their efforts to promote bird conservation among bird keepers. Agrawal (2006) outlines the importance of enrolling those who are the targets of policy as producers of voluntary rules and norms of practice and as accomplices in enforcement. Effective implementation of a more blended approach to governance with a strong non-state, market-driven element would help transform bird keepers into people who care about the domain being regulated (i.e. environmental subjects; Agrawal, 2006) because it would introduce conservation as a conceptual category that organizes their thinking and prompts them to act in new ways. In short, whilst the approach outlined might not directly improve the status of wild bird populations it could contribute to creating the cultural context from which more influential calls for conservation could arise.

\section{Acknowledgements}

We are indebted to many people who helped with this research. Farquhar Stirling and Dindin Kusdinar at Nielsen Indonesia and Peter Wood made invaluable contributions to the quantitative research. Made Prana, Endang Budi Utama and the committee of Pelestari Burung Indonesia, and Willy Rombang, Fahrul Amama and Edho all participated in the qualitative research and provided valuable insights. Shinta Puspitisari conducted a phone interview survey of bird keepers. We thank anonymous reviewers for their constructive comments. This research was funded by Defra's Darwin Initiative, which draws on biodiversity expertise within the UK to help protect and enhance biodiversity globally.

\section{References}

Agrawal, A. (2006) Environmentality. Technologies of Government and the Making of Subjects. Duke University Press, Durham, USA.

Bernstein, S. \& Cashore, B. (2004) Non-state global governance: is forest certification a legitimate alternative to a global forest convention? In Hard Choices, Soft Law. Voluntary Standards in Global Trade, Environment and Social Governance (eds J.J. Kirton \& M.J. Trebilcock), pp. 33-63. Ashgate Publishing, Burlington, USA. 
BirdLife International (2011) BirdLife Data Zone. Http://www.birdlife. org/datazone/home [accessed 1 August 2011].

Burung Nusantara (2011) Birding in Indonesia. Http://www.burungnusantara.org/birding-indonesia [accessed 1 August 2011].

Cashore, B., Auld, G. \& Newsom, D. (2003) Forest certification (eco-labeling) programs and their policy-making authority: explaining divergence among North American and European case studies. Forest Policy and Economics, 5, 225-247.

CÉSARD, N. (2004) Harvesting and commercialisation of kroto (Oecophylla smaragdina) in the Malingping area, West Java, Indonesia. In Forest Products, Livelihoods and Conservation. Case Studies of Non-Timber Product Systems (eds K. Kusters \& B. Belcher), pp. 61-67. Center for International Forestry Research, Bogor, Indonesia.

Greene, C.J., Caracelli, V.J. \& Graham, W.F. (1989) Toward a conceptual framework for mixed-method evaluation design. Educational Evaluation and Policy Analysis, 11, 255-274.

Gulbrandsebn, L. (2004) Overlapping public and private governance: can forest certification fill the gaps in the global forest regime? Global Environmental Politics, 4, 75-99.

Holmes, D. (1995) Editorial. Kukila, 7, 85-90.

Jepson, P. (2008) Orange-headed thrush Zoothera citrina and the avian X-factor. Birding Asia, 9, 58-61.

JEPSON, P. (2010) Towards an Indonesian bird conservation ethos: reflections from a study of bird-keeping in the cites of Java and Bali. In Ethno-Ornithology (eds S. Tilman \& A. Gosler), pp. 313-330. Earthscan, London, UK.

Jepson, P. \& LadLe, R.J. (2006) Bird keeping in Indonesia: conservation impacts and the potential for substitution-based conservation responses. Oryx, 39, 442-448.

Jepson, P. \& LAdLe, R.J. (2009) Developing new policy instruments to regulate consumption of wild birds: socio-demographic characteristics of bird keeping in Java and Bali. Oryx, 43, 364-374.

Jepson, P., Prana, M., Sujatnika \& Amana, F. (2008) Developing a certification system for captive-bred birds in Indonesia. TRAFFIC Bulletin, 22, 7-9.
Jordan, A., Wurzel, R.K.W. \& Zito, A. (2005) The rise of 'new' policy instruments in comparative perspective: has governance eclipsed government? Political Studies, 53, 477-496.

Kristianto, I. \& Jepson, P. (2011) Harvesting orange-headed thrush Zoothera citrina chicks in Bali, Indonesia: magnitude, practices and sustainability. Oryx, 45, 492-499.

Lemos, M.C. \& Agrawal, A. (2006) Environmental governance. Annual Review of Environmental Resources, 31, 297-326.

Manning, C. (2003) Labor Policy and Employment Creation: An Emerging Crisis? USAID/ECG, Jakarta, Indonesia.

NASH, S.V. (1993) Sold for a Song. The Trade in Southeast Asian Non-CITES Birds. TRAFFIC International, Cambridge, UK.

Toer, P.A. (1984) This Earth of Mankind. Penguin, London, UK.

World BANK (2006) Making the New Indonesia Work for the Poor. World Bank, Jakarta, Indonesia.

\section{Biographical sketches}

PAUL JePSON leads an interdisciplinary research group on conservation governance and his current research focuses on four interlinked themes: how conservation could build influence in situations where the engagement of governmental or corporate bodies is absent, the role and agency of bio-cultural terms (e.g. extinction, flagships) in producing the institutional practices of conservation, the role of species and technologies in the assembly and behaviour of conservation networks, and the interplay of western-formulated conservation policy instruments with local cultural and resource management institutions. RICHARD LADLE has diverse and interdisciplinary research interests that span conservation practice, science communication, extinction theory, biogeography and theoretical ecology. SUJATNIKA is a founding director of Aksenta, a consulting company specializing in improving clients' capacity to manage their environmental and social challenges. He has facilitated strategic planning for conservation bodies in Indonesia and is currently busy with High Conservation Value and Social Impact Assessments. 